\title{
Dependence of precipitation on temperature at Florence and Livorno (Italy)
}

\author{
T. Adri Buishand*, Theo Brandsma \\ Royal N etherlands Meteorological Institute (KN MI), PO Box 201, 3730 AE De Bilt, The Netherlands
}

\begin{abstract}
Papers dealing with precipitation scenarios for a potentially warmer climate have often ignored the relationship between precipitation and temperature. Although the atmosphere has a larger capacity to hold water vapour at higher temperatures, plots of the mean wet-day precipitation amounts versus temperature may not reveal a clear positive relationship. This phenomenon is studied in detail for Florence and Livorno (Italy). Vorticity and the difference between the land and sea surface temperatures are 2 important factors that determine precipitation at these sites. The wet-day precipitation amount is explored as a function of these 2 variables and temperature using an iterative smoothing technique. The estimated functions show a marked increase in the mean wet-day precipitation amount with increasing temperature $\left(-6 \%{ }^{\circ} \mathrm{C}^{-1}\right)$. The differences between the smoothed relations for Florence and Livorno are small and the smooths for the winter and summer halves of the year are also quite similar. Besides the mean wet-day precipitation amounts, the mean wet-hour amounts (mean rainfall intensities) of each day with rain are also analysed. These show a much stronger increase with increasing temperature $\left(-11 \%{ }^{\circ} \mathrm{C}^{-1}\right)$, which is partly due to a decrease of rainfall duration with increasing temperature.
\end{abstract}

KEY WORDS: Climate-change scenario - Precipitation - Temperature $\cdot$ Sea surface temperature $\cdot$ Italy . Loess smoother $\cdot$ Generalized linear models

\section{INTRODUCTION}

There is a link between the amount of precipitation and temperature. An important factor is the increase of the saturated vapour pressure with increasing temperature. Warm air can therefore contain more moisture than cold air. M ainly because of this temperature effect on atmospheric moisture, General Circulation Models (GCMs) predict that the global warming resulting from the increased atmospheric greenhouse gas concentrations will be accompanied by an increase in the global mean precipitation of 1.5 to $3 \%{ }^{\circ} \mathrm{C}^{-1}$ (IPCC 1990, 1992, Boer 1993, Hulme 1994, Henderson-Sellers et al. 1995, Hulme et al. 1998). Besides the effect on the atmospheric water content, temperature also controls the strength of convection.

The dependence of precipitation on temperature is a somewhat neglected topic in the literature on climatechange scenarios. Various linkages between precipita-

*E-mail: buishand@knmi.nl tion and the large-scale circulation have been proposed in the literature on statistical downscaling (Bárdossy \& Plate 1992, Hughes et al. 1993, von Storch et al. 1993). There is, however, growing evidence that the circulation changes alone are insufficient to explain the changes in mean precipitation as simulated in climate model experiments with increased greenhouse gas concentrations (M atyasovszky et al. 1993, J ones et al. 1997, Wilby \& Wigley 1997).

The influence of temperature has been incorporated in an indirect, or sometimes a direct, way in a number of studies. In order to generate daily precipitation sequences for a doubled $\mathrm{CO}_{2}$ climate, $\mathrm{M}$ atyasovszky et al. (1993) used the changes in the average height of the $500 \mathrm{hPa}$ level in a climate model simulation experiment to perturb the parameters of their stochastic precipitation model. The changes in precipitation are then related to the higher temperatures in the lower atmosphere because of their influence on the height of the $500 \mathrm{hPa}$ level. Schär et al. (1996) performed an experiment with a Regional Climate Model to explore the 


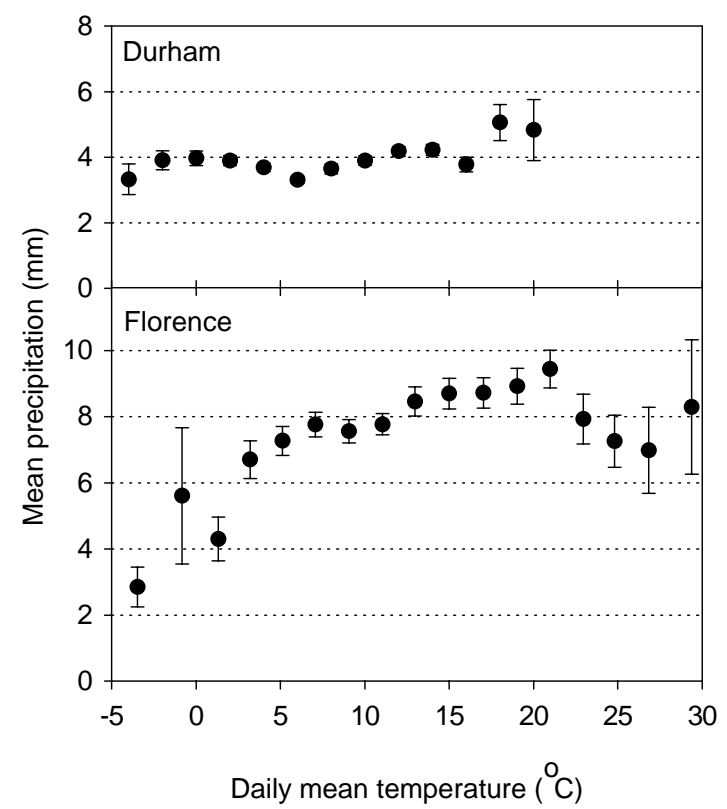

Fig. 1. Relationship between daily mean precipitation amount and daily mean temperature for wet days $(0.3 \mathrm{~mm}$ or more) at Durham (1931-1990) and Florence (1935-1987). The error bars give the SE of the mean precipitation within each class. The total number of wet days for the 2 stations are 10128 and 4529, respectively

changes in precipitation within Europe resulting from a $2^{\circ} \mathrm{C}$ warming, keeping the relative humidity and circulation patterns unchanged. In a later version of that experiment (Frei et al. 1998), particular attention was given to changes in heavy precipitation.

A number of authors have included $700 \mathrm{hPa}$ temperatures (Cubasch et al. 1996), 1000 - $500 \mathrm{hPa}$ thickness (Cavazos 1997) or specific humidity at pressure levels (Crane \& Hewitson 1998) in their downscaling models. Wilby \& Wigley (1997) observed that using 700 and $500 \mathrm{hPa}$ temperatures as additional explanatory variables in an artificial neural network, relating observed precipitation and circulation variables, had little effect on the predicted changes between present and future climates. They suggested that the driving GCM had a stronger precipitation-temperature link than in the real world.

Klein Tank \& Buishand (1993) examined the relationship between the mean wet-day precipitation amount and temperature at De Bilt, an inland station in The Netherlands. The relationship was used to obtain scenarios of daily precipitation for a doubled $\mathrm{CO}_{2}$ Climate. In a subsequent study (Brandsma \& Buishand 1997), their method was extended to Bern, Neuchâtel and Payerne in western Switzerland. The direction and strength of the atmospheric flow were included to account for the influence of orography on precipita- tion. The identification of a clear effect of the air temperature on precipitation can further be hampered at coastal sites, where precipitation is strongly controlled by the sea surface temperature. As an example, Fig. 1 shows the mean wet-day precipitation amount as a function of daily temperature for Durham (England) and Florence (Italy), where a day is considered to be wet if the amount of precipitation is $0.3 \mathrm{~mm}$ or more. There is little change in the mean wet-day precipitation amount in these diagrams, in particular for Durham. This is in contrast with similar diagrams for De Bilt in Buishand \& Klein Tank (1996) and western Switzerland in Brandsma \& Buishand (1997). Obviously, a potential temperature effect at Durham and Florence is obscured by other factors. These factors have to be included in statistical models that describe the effect of temperature on precipitation.

In this paper, precipitation at Florence and Livorno in Italy (Fig. 2) is studied. Both daily and hourly precipitation amounts are analysed. Section 2 gives an outline of the statistical methods used. The results are presented in Section 3. Section 4 concludes the paper with a discussion.

\section{STATISTICAL MODELLING}

This section gives some background of the statistical linkage of precipitation to other variables. The wet-day precipitation amounts are considered first. The hourly precipitation amounts can be modelled in a similar way. A separate model for the rainfall duration is discussed at the end of this section.

2.1. Wet-day precipitation. The wet-day precipitation amounts, P, have a highly skewed distribution. Days with small amounts predominate. Further, the standard deviation of $\mathrm{P}$ depends on the predictor variable(s). An interesting point is that the change in the coefficient of variation, $\mathrm{CV}$, for different values of the predictor variable(s) is generally much smaller than that in the standard deviation. In quite a number of cases $C V$ is constant.

Data with a constant CV can be modelled in 2 different ways (McCullagh \& Nelder 1989). The most widespread method is to define a linear model for the logarithm of $\mathrm{P}$. The model can be fitted by ordinary least squares. For the wet-day precipitation amounts, this approach meets, however, 2 difficulties. First, the logarithm is sensitive to roundings of small precipitation amounts, and, second, the assumption of a constant CV turns out to be crucial for the estimation of the mean of P from the fitted model (Klein Tank \& Buishand 1993). The alternative is to describe the untransformed wetday precipitation amounts by a generalized linear 


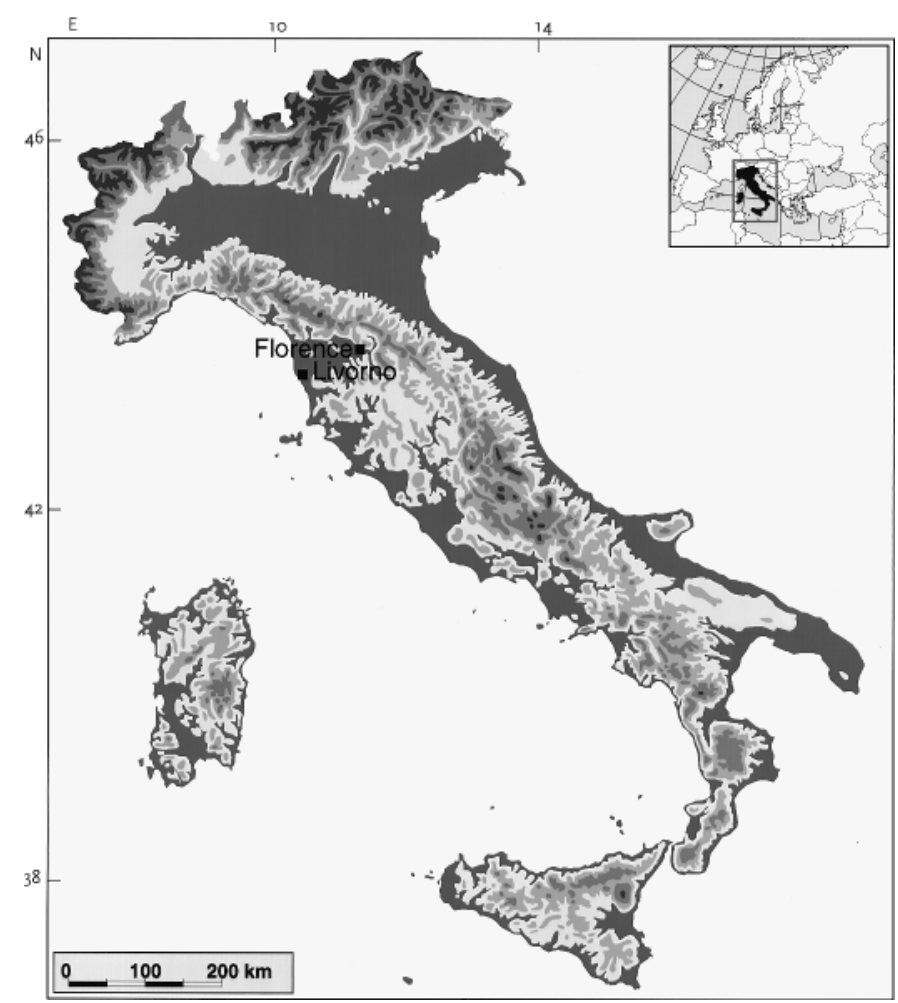

Fig. 2. Position of Florence and Livorno within Italy

model. Parameter estimation requires then an Iteratively Reweighted Least Squares (IRLS) technique. This method can easily be extended to cases where CV is not constant. The second approach is therefore preferred in this study. The linearity assumption is relaxed by modelling the regression surfaces as a sum of arbitrary smooth terms.

First, the situation considered is that there is only 1 predictor variable, $\mathrm{X}$, for $\mathrm{P}$. For the statistical techniques in this study, it is useful to represent the relationship between $\mathrm{P}$ and $\mathrm{X}$ as

$$
P=\exp [g(X)]+\varepsilon
$$

where $g(X)$ is a function of $X$ and $\varepsilon$ is a random error with zero mean. The first term on the right-hand side gives the expected value $\mu$ of $P$ :

$$
\mu=E(P)=\exp [g(X)]
$$

The change of the mean precipitation amount with $X$ is thus determined by the function $g(X)$. For the linear model

$$
g(X)=a+b X
$$

the mean increases exponentially with increasing $X$. An essential condition for the IRLS technique is that $g(X)$ is linear in unknown regression coefficients like a and $\mathrm{b}$.
Because of the exponential function in Eq. (1) the mean $\mu$ cannot be negative. Furthermore, a constant change, $\Delta X$, of $X$ leads to a relative change in the mean wet-day precipitation amount of $\exp [g(X+\Delta X)-g(X)]$, which resembles the popular proportional adjustments of observed precipitation in climate-change scenarios.

$\varepsilon$ is bounded by $-\mu$ because $P$ must be positive. A more important aspect of parameter estimation is that the variance of $\varepsilon$ depends on $\mu$ as well. For the case of a constant CV, var $\varepsilon=c^{2} \mu^{2}$, where $c$ is a constant.

The IRLS technique can be applied both to the individual observations and to the mean wet-day precipitation amounts for various class intervals of the predictor variable, like the temperature classes in Fig. 1 (Buishand \& Klein Tank 1996). The latter is preferred here. The within-class variation of the individual wetday precipitation amounts provides a check on the constancy of CV.

The linear form of $g(X)$ in Eq. (3) often turns out to be too restrictive. Cleveland's (1979) locally weighted running line or loess smoother was used here to visualise departures from linearity. Although that smoother was originally developed as a non-parametric regression technique for the case of constant error variance, it can be generalised to the situation where var $\varepsilon$ depends on $\mu$ (Hastie \& Tibshirani 1990). The estimate $\hat{g}\left(X_{0}\right)$ for $X=X_{0}$ is then based on a weighted IRLS fit of the linear model in Eq. (3), using only data $\left(X_{k}, P_{k}\right)$ in a neighbourhood $N\left(X_{0}\right)$ of $X_{0}$, where the weight is large if $X_{k}$ is close to $X_{0}$ and small if it is not. The size of $N\left(X_{0}\right)$ controls the smoothness of the fitted relationship. Small neighbourhoods result in a relatively rough curve. The fraction $\lambda$ of points in $N\left(X_{0}\right)$ is known as the span of the smoother. Further details about the application of the loess smoother to precipitation relationships can be found in Brandsma \& Buishand (1997).

When there are several predictor variables $X_{1}, X_{2}, \ldots$, $X_{p}$ the model for the wet-day precipitation amounts may take the form

$$
P=\exp \left[g\left(X_{1}, X_{2}, \ldots, X_{p}\right)\right]+\varepsilon
$$

In this study $g\left(X_{1}, X_{2}, \ldots, X_{p}\right)$ is taken to be additive in the predictor effects:

$$
P=\exp \left[a+g_{1}\left(X_{1}\right)+g_{2}\left(X_{2}\right)+\ldots+g_{p}\left(X_{p}\right)\right]+\varepsilon
$$

Non-parametric smoothing assumes that the $g_{i}\left(X_{i}\right)$ are smooth functions, subject to the condition $E\left[g_{i}\left(X_{i}\right)\right]=0$ to avoid free constants. The form of the functions $g_{i}\left(X_{i}\right)$ can be explored by the univariate loess smoother using the iterative backfitting algorithm (Hastie \& Tibshirani 1990). That algorithm also applies when the right-hand side of Eq. (5) contains linear terms like $a_{i} X_{i}$ and $a_{j} X_{j}$.

2.2. Hourly precipitation. Hourly precipitation exhibits a marked autocorrelation. Difficulties with the effects of autocorrelation on statistical inference can be 
avoided by analysing the mean wet-hour precipitation amount, $\mathrm{H}$, on days with rain, i.e. the daily precipitation amount divided by the number of rain hours, instead of all hourly values. The variable $\mathrm{H}$ can be described by the same type of model as that for P. In order to compare the results for $\mathrm{P}$ and $\mathrm{H}$, it is useful to consider the effect of the predictor variables on the number of rain hours. For the days with rain hours, the proportion $\mathrm{F}$ of these rain hours can be represented as

$$
F=\Pi\left(X_{1}, X_{2}, \ldots, X_{p}\right)+\varepsilon
$$

where the deterministic part is given by

$$
\begin{aligned}
& \Pi\left(X_{1}, X_{2}, \ldots, X_{p}\right)= \\
& \frac{\exp \left[a+g_{1}\left(X_{1}\right)+g_{2}\left(X_{2}\right)+\ldots+g_{p}\left(X_{p}\right)\right]}{1+\exp \left[a+g_{1}\left(X_{1}\right)+g_{2}\left(X_{2}\right)+\ldots+g_{p}\left(X_{p}\right)\right]}
\end{aligned}
$$

and $\varepsilon$ is random error with zero mean. The model defined by Eqs. (6) \& (7) is known as the logistic model (Hastie \& Tibshirani 1990). Eq. (7) ensures that $\Pi$ lies between 0 and 1 . Although every continuous distribution function having support on the entire real axis can be used for this purpose, the logistic distribution is the most popular one. Alternatives were not considered here, particularly because of the large flexibility attained with the use of the non-specified functions $g_{i}\left(X_{i}\right)$.

As in the model for the precipitation amounts, $\varepsilon$ depends on the deterministic part. In particular its variance is modelled as

$$
\operatorname{var} \varepsilon=\sigma^{2} \Pi(1-\Pi) / 24
$$

where $\sigma^{2}$ denotes the dispersion parameter (McCullagh \& Nelder 1989). For $\sigma^{2}=1$, Eq. (8) reduces to the binomial variance which applies to the situation in which rain occurrence is purely random. Because of the persistence of the weather, rain hours tend to occur in clusters. Rain days with a very large proportion of rain hours are therefore much more likely than in the case of pure random variation. For this reason, the variance of $\varepsilon$ tends to be larger than the binomial variance and thus $\sigma^{2}>1$, which is known as over-dispersion.

\section{DATA ANALYSIS}

Florence and Livorno are both situated to the southwest of the Apennine mountain range in the northwestern part of Italy (Fig. 2) at an altitude of 76 and $3 \mathrm{~m}$, respectively. Mean annual rainfall is about $800 \mathrm{~mm}$ at these sites. Daily precipitation and temperature data were obtained via Politecnico di Milano for the periods 1935 to 1987 for Florence and 1924 to 1941 and 1951 to 1979 for Livorno. Supplementary hourly data were provided for the period 1962 to 1986 . These data were not adjusted to the daily data. Daily mean sea level pressure (MSLP) data on a $5^{\circ}$ latitude by $10^{\circ}$ longitude grid from the UK M eteorological Office were used to account for the effect of atmospheric flow. As in Brandsma \& Buishand (1997) the grid was centred at $45^{\circ} \mathrm{N}, 5^{\circ} \mathrm{E}$. Because of the vicinity of the Mediterranean Sea, the difference $D$ between the land and sea surface temperatures was included in the statistical analysis:

$$
\mathrm{D}=\mathrm{T}-\mathrm{SST}
$$

where $T$ is the local daily air temperature at Florence or Livorno and SST is the daily sea surface temperature for the area $40^{\circ}-45^{\circ} \mathrm{N}, 5^{\circ}-10^{\circ} \mathrm{E}$. The latter was obtained from the monthly SST anomalies in the J ones data set (J ones et al. 1991) and the long-term mean SSTs in Bottomley et al. (1990), using an iterative cubic spline interpolation procedure that preserves the monthly SSTs, as proposed by Harzallah \& Sadourny (1995). In general, a relatively warm sea (negative D) enhances precipitation, whilst a relatively cold sea (positive $\mathrm{D}$ ) has the opposite effect. Although there is a rather strong positive correlation between $\mathrm{D}$ and $\mathrm{T}$ (correlation coefficient about 0.8 for the daily data considered here), it is shown later on that their effects on the wet-day precipitation amounts can be clearly distinguished.

\subsection{Wet-day precipitation}

Precipitation-temperature diagrams like those in Fig. 1 were plotted for different sectors of flow direction. Despite the barrier effect of the Alpine-A pennine range, these diagrams show little variation. Vorticity turned out to be a much more important factor than flow direction. For the wet-day precipitation amounts at Florence and Livorno, Eq. (5) therefore takes the form

$$
P=\exp \left[a+g_{1}(T)+g_{2}(D)+g_{3}(Z)\right]+\varepsilon
$$

where $Z$ is an index of the total shear vorticity. Details about the calculation of $Z$ from the gridded M SLP data can be found in J ones et al. (1993). The variable $Z$ is only weakly correlated with $T$ and $D$.

The model was first fitted to all wet-day precipitation amounts and then to the amounts for the winter halfyear (October to M arch) and summer half-year (April to September) separately, in order to investigate seasonal variation in the effects of the predictor variables. For each fit the mean wet-day precipitation amounts for different categories of predictor variables were considered $(\sim 210$ categories for the whole year, 170 for the winter half-year and 110 for the summer half-year). 

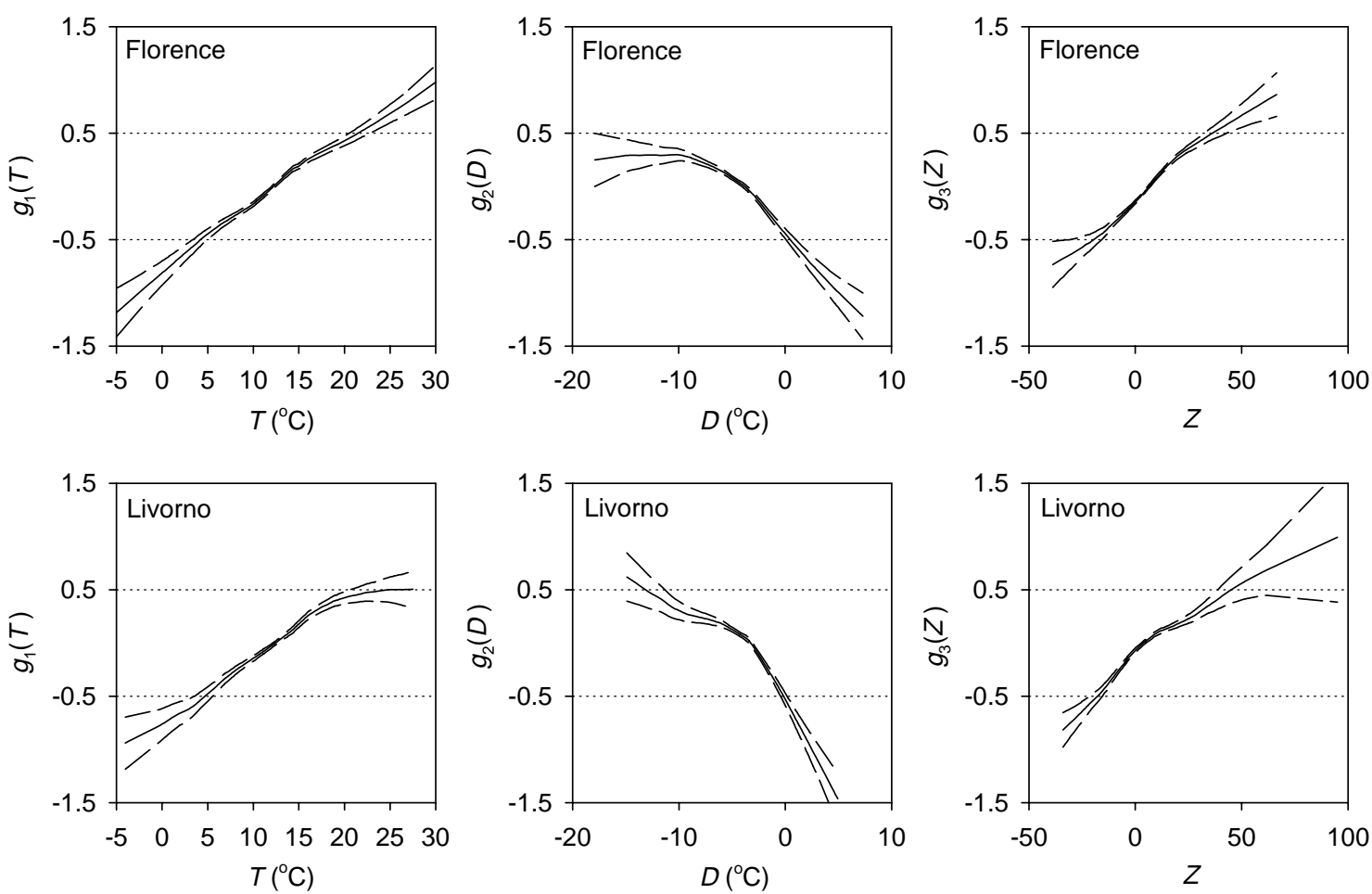

Fig. 3. Estimates of the functions $g_{1}(T), g_{2}(D)$ and $g_{3}(Z)$ in Eq. (10) for wet days at Florence and Livorno. Dashed curves are pointwise 1 SE bands (Chambers \& Hastie 1993, p 303-304); vorticity units are geostrophic, expressed as hPa per $10^{\circ}$ latitude at $45^{\circ} \mathrm{N}$ (1 unit is equivalent to $0.78 \times 10^{-6} \mathrm{~s}^{-1}$ )

The iterative estimation of $g_{1}(T), g_{2}(D)$ and $g_{3}(Z)$ requires a description of $C V$. In this study, a simple linear relation was assumed:

$$
\mathrm{CV}=\alpha+\beta \mathrm{T}+\gamma \mathrm{D}+\delta \mathrm{Z}
$$

The average $\mathrm{CV}(\overline{\mathrm{CV}})$ and the estimates of $\alpha, \beta, \gamma$ and $\delta$ are presented in Table 1 . A s in Brandsma \& Buishand (1997) the coefficients were estimated by fitting Eq. (11) to the sample CVs of the categories of the predictor variables having 2 wet days or more ( 140 categories for the whole year, 100 for the winter half-year and 80 for the summer half-year). The value of $\overline{C V}$ is the weighted average of these sample CVs (with weights inversely proportional to the number of wet days in the appropriate category). For all cases $\overline{\mathrm{CV}}$ is about 1 , which is comparable to the values given in Buishand \& Klein Tank (1996) for The N etherlands and in Brandsma \& Buishand (1997) for Switzerland. For Florence and Livorno, Table 1 further shows that in most cases $T$ has a statistically significant influence on the CV of the wet-day precipitation amounts; for Florence there is a significant influence of $Z$ if the whole year or the winter half-year is considered.

Fig. 3 presents the estimates of the functions $g_{1}(T)$, $g_{2}(D)$ and $g_{3}(Z)$. Here no distinction is made between precipitation in the winter and summer halves of the year. The spans $\lambda_{T}, \lambda_{D}$ and $\lambda_{Z}$ in the iterative smoothing procedure were all set equal to 0.5 . The plots for Florence and Livorno are quite similar. Both $g_{1}(T)$ and $g_{3}(Z)$ are increasing functions, in accordance with the general expectation that $P$ should be positively related to $T$ and $Z$. The plot for $g_{2}(D)$ delineates a clearly negative relationship between $P$ and $D$. The opposite effects of $T$ and $D$ on $P$, and the positive correlation between these 2 predictor variables, explains why the mean wet-day precipitation amounts show little variation with $\mathrm{T}$ in Fig. 1 . The sea tends to be relatively warm at low temperatures (negative D) and relatively

Table 1. Average coefficient of variation ( $\overline{\mathrm{CV}})$ and estimates of the parameters $\alpha, \beta, \gamma$ and $\delta$ in Eq. (11). The given estimates are significant at the $5 \%$ level

\begin{tabular}{|llccccc|}
\hline Station & Period & $\overline{\mathrm{CV}}$ & $\alpha$ & $\beta$ & $\gamma$ & $\delta$ \\
\hline Florence & Year & 1.099 & 1.031 & 0.0070 & - & -0.0057 \\
& Winter & 1.077 & 1.118 & - & - & -0.0063 \\
& Summer & 1.104 & 0.646 & 0.0252 & - & - \\
Livorno & Year & 1.189 & 0.810 & 0.0275 & - & - \\
& Winter & 1.084 & 0.864 & 0.0193 & - & - \\
& Summer & 1.266 & 1.266 & - & - & - \\
\hline
\end{tabular}



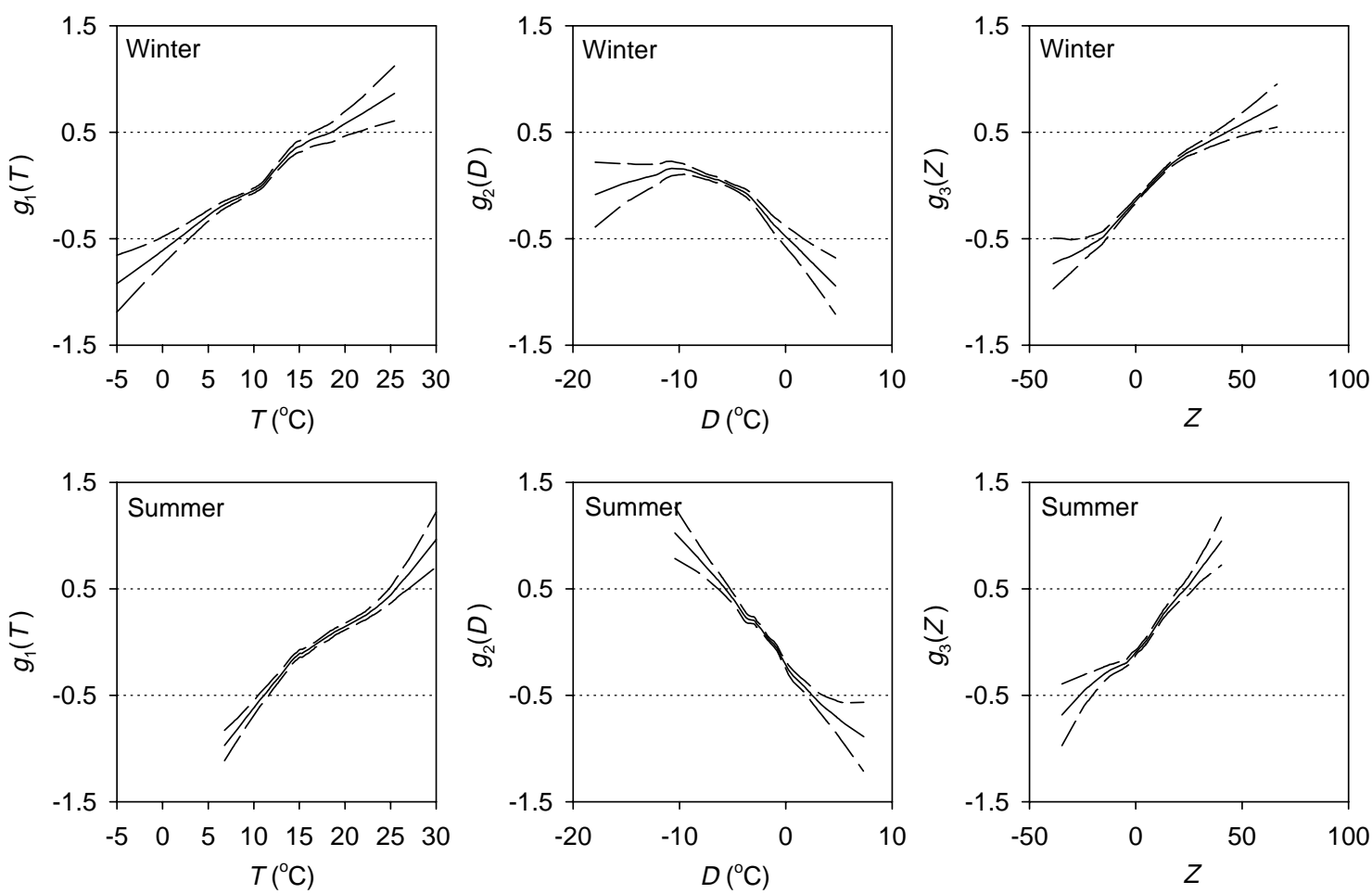

Fig. 4. Estimates of the functions $g_{1}(T), g_{2}(D)$ and $g_{3}(Z)$ in Eq. (10) for wet days at Florence in the winter and summer halves of the year. Dashed curves and vorticity units are explained in Fig. 3 legend

cold at high temperatures (positive D). The expected positive effect of a temperature increase on $P$ is counterbalanced in Fig. 1 by the influence of the associated increase in $D$.

For Florence, Fig. 4 shows the shapes of $g_{1}(T), g_{2}(D)$ and $g_{3}(Z)$ from the separate fits to the wet-day precipitation amounts in the winter and summer halves of the year. As in Fig. 3 , the spans $\lambda_{T}, \lambda_{D}$ and $\lambda_{Z}$ were set equal to 0.5 . The plots for the 2 separate seasons look quite similar to those in Fig. 3 for the whole year. The almost parallel shift of $g_{1}(T)$ to the right for the summer half-year is due to the higher temperatures in summer. Such a shift does not influence the effect of a systematic temperature increase on precipitation, which is determined by the slope of $g_{1}(T)$. Similar results were obtained for Livorno. There was also high correspondence between the estimates of $g_{1}(T), g_{2}(D)$ and $g_{3}(Z)$ in a separate analysis of the data from Florence for the first half ( $\mathrm{anuary}$ to J une) and the second half ( $\mathrm{July}$ to December) of the year.

In order to obtain a rough quantitative estimate of the temperature effect on the mean wet-day precipitation amounts, the analysis was repeated with the model

$$
P=\exp \left[a+b T+g_{2}(D)+g_{3}(Z)\right]+\varepsilon
$$

The function $g_{1}(T)$ is thus taken to be linear. The departures from linearity in Figs. $3 \& 4$ are generally small. The linearity of $g_{1}(T)$ implies that an increase in $\mathrm{T}$ of $1^{\circ} \mathrm{C}$ leads to a relative change in the mean wet-day precipitation amounts of $\exp (\mathrm{b})$, assuming that $D$ and $Z$ remain unchanged. Table 2 presents the estimates of a and $b$ together with their standard errors. The standard errors are quite large due to the positive correlation between $T$ and $D$ and because a large proportion of the wet-day precipitation variance is not explained by the model. For the parameter $b$, the relative standard error ranges between 10 and $20 \%$. The estimates of that parameter in Table $2 \mathrm{imply}$ a relative increase in the mean wet-day precipitation amounts of 4 to $8 \%$ ${ }^{\circ} \mathrm{C}^{-1}$. This increase is comparable to that in the satu-

Table 2. Estimates of the parameters $a$ and $b$ in Eq. (12) and their standard errors (in parentheses)

\begin{tabular}{|llcc|}
\hline Station & Period & $a$ & $b$ \\
\hline Florence & Year & $1.366(0.060)$ & $0.058(0.0048)$ \\
& Winter & $1.448(0.078)$ & $0.064(0.0079)$ \\
& Summer & $0.846(0.122)$ & $0.066(0.0068)$ \\
Livorno & Year & $1.448(0.071)$ & $0.055(0.0058)$ \\
& Winter & $1.360(0.090)$ & $0.074(0.0086)$ \\
& Summer & $1.388(0.159)$ & $0.039(0.0089)$ \\
\hline
\end{tabular}




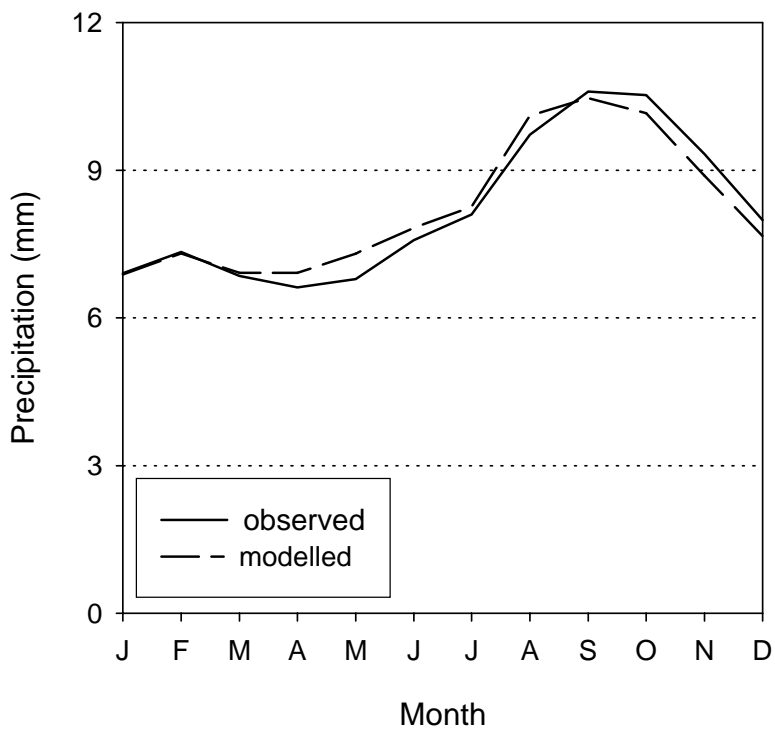

Fig. 5. Observed and modelled monthly mean wet-day precipitation amounts at Florence

rated vapour pressure $\left(-6\right.$ to $\left.7 \%{ }^{\circ} \mathrm{C}^{-1}\right)$ and to that in the mean precipitation for the Mediterranean subdomain in the model experiment of Frei et al. (1998) with unchanged relative humidity and circulation patterns. It also reasonably agrees with the change in mean precipitable water for temperatures between 0 and $31^{\circ} \mathrm{C}$ given in Gaffen et al. (1992) for continental and island stations in the extratropics. These changes are, however, much larger than the values found for the global mean precipitation in GCM experiments ( -1.5 to $3 \%$ ${ }^{\circ} \mathrm{C}^{-1}$ ) and the changes in the mean annual precipitation from the fitted statistical relationships for The Netherlands and western Switzerland, as reported in Buishand \& Klein Tank (1996) and Brandsma \& Buishand (1997), respectively.

\subsection{Reproduction of the annual cycle and interannual variability}

The mean wet-day precipitation amounts at Florence and Livorno show a clear annual cycle with a maximum in September-October. The model may not reproduce this annual cycle, especially when the relationship between $\mathrm{P}$ and the predictor variables is assumed to be constant over the year, as in Fig. 3 . Therefore the observed monthly mean wet-day precipitation amounts were compared with those according to the constant relationship. The latter were obtained by replacing the observed precipitation amount of each wet day by its expected value from the model in Eq. (10). Fig. 5 shows that the observed annual cycle at Florence is reproduced well. There is a small under-estimation during the winter half-year and an over-estimation during the summer half-year. The inclusion of $D$ appeared to be important to achieve a satisfactory reproduction of the monthly mean wet-day precipitation amounts (Brandsma \& Buishand 1996). The observed monthly mean wet-day precipitation amounts in Fig. 5 explain $2.1 \%$ of the overall wet-day precipitation variance. For the fitted regression model the proportion of explained variance is $7.2 \%$.

The quality of the model in Eq. (10) was checked further by reconstructing the time series of annual precipitation amounts. Fig. 6 shows that the variation of the estimated values for Florence is reasonably coherent with that of the observed annual precipitation amounts. The reconstructed annual precipitation amounts explain $57 \%$ of the variance. A large part of the explained variance is, however, due to the use of the observed sequence of wet and dry days in the reconstructed annual precipitation amounts. Replacing the observed precipitation amount of each wet day by the overall average wet-day precipitation amount

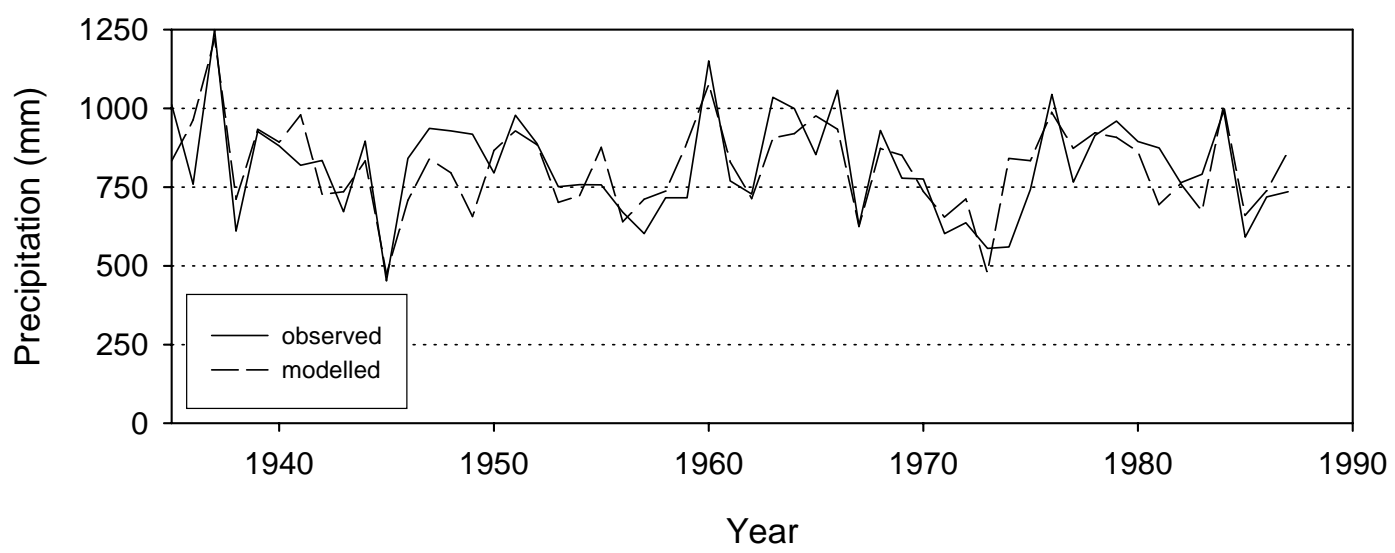

Fig. 6. Observed and modelled annual precipitation amounts at Florence 

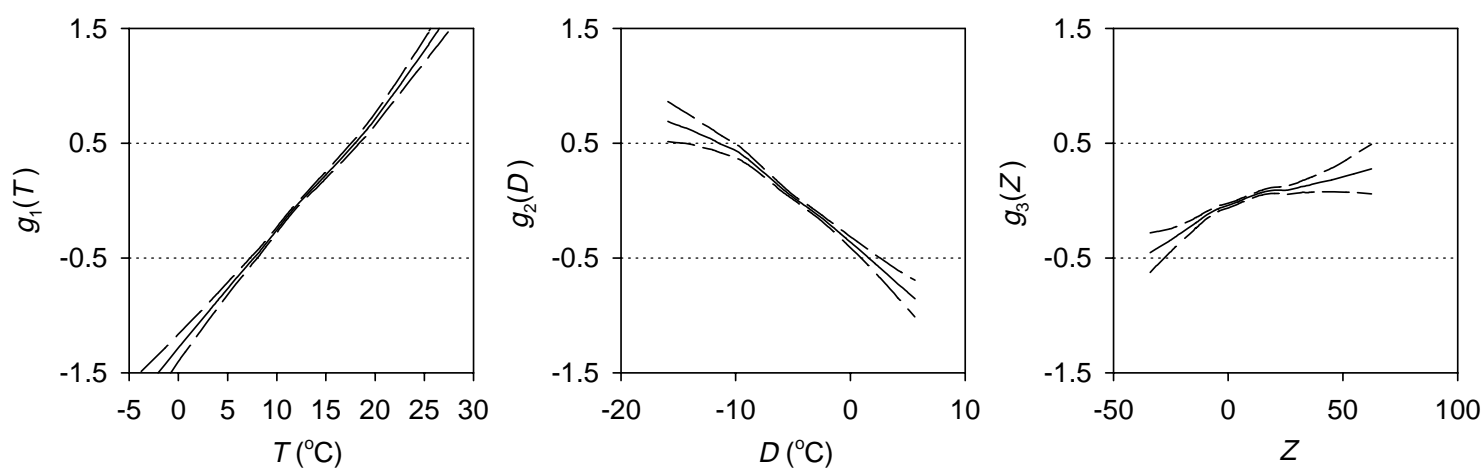

Fig. 7. Estimates of the functions $g_{1}(T), g_{2}(D)$ and $g_{3}(Z)$ in Eq. (10) for wet-hour precipitation amounts on days with rain at Florence. Dashed curves and vorticity units are explained in Fig. 3 legend
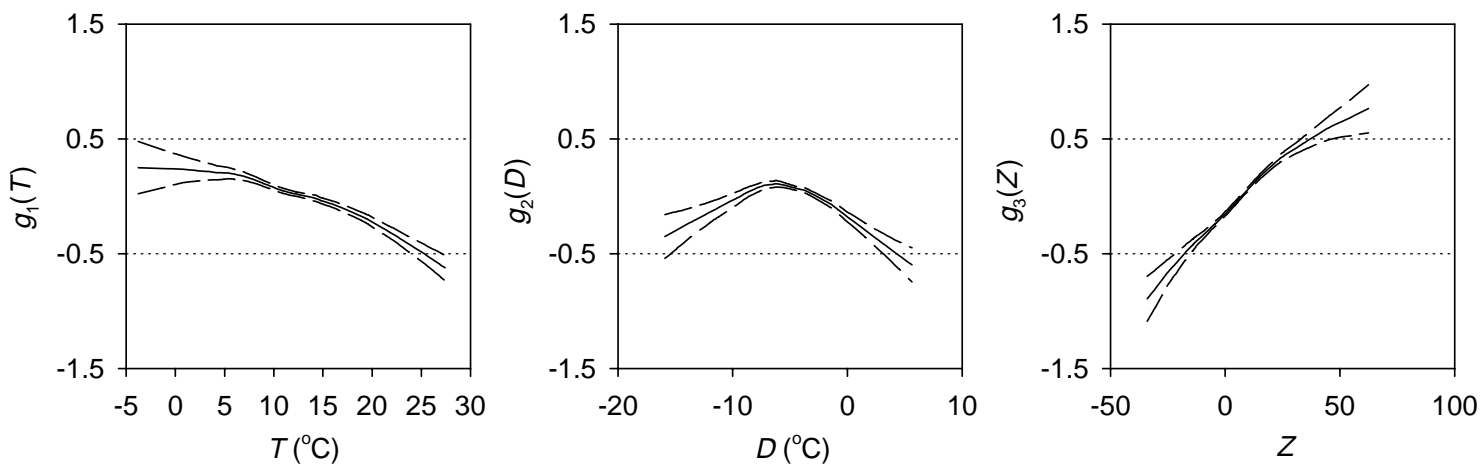

Fig. 8. Estimates of the functions $g_{1}(T), g_{2}(D)$ and $g_{3}(Z)$ in Eq. (13) for the rain hours at Florence. Dashed curves and vorticity units are explained in Fig. 3 legend

$(\bar{P}=8.1 \mathrm{~mm})$ results in a series of annual precipitation amounts that only explains $48 \%$ of the variance.

\subsection{Hourly precipitation}

Eq. (5) was also fitted to the mean wet-hour precipitation amounts, $H$, using the same spans $\lambda_{T}, \lambda_{D}$ and $\lambda_{Z}$ as in the iterative smoothing procedure of the daily values. All hours with measurable rain were considered. The analysis here is restricted to Florence only. Fig. 7 presents the estimates of $g_{1}(T), g_{2}(D)$ and $g_{3}(Z)$. Eq. (11) with $\alpha=0, \beta=0.054, \gamma=-0.054$ and $\delta=0$ was used in this fit to describe the dependence of $C V$ on the predictor variables $(\overline{\mathrm{CV}}=0.937)$. As for the daily data, $g_{1}(T)$ is almost linear. The effect of a temperature increase is, however, much stronger for the mean wethour precipitation amounts. With $\hat{b}=0.099$ as the estimate of $\mathrm{b}$ in Eq. (12), it follows that the increase in the mean of $\mathrm{H}$ is about $10.4 \%{ }^{\circ} \mathrm{C}^{-1}$ (was $6.0 \%{ }^{\circ} \mathrm{C}^{-1}$ for the wet-day precipitation amounts $\mathrm{P}$ ). This difference can partly be explained by analysing the effect of temperature on rainfall duration. Therefore the logistic model, with $X_{1}=T, X_{2}=D$ and $X_{3}=Z$ in Eqs. (6) \& (7), was fit- ted to the proportion $\mathrm{F}$ of rain hours. The expected value of $F$ is then given by

$$
\Pi(T, D, Z)=\frac{\exp \left[a+g_{1}(T)+g_{2}(D)+g_{3}(Z)\right]}{1+\exp \left[a+g_{1}(T)+g_{2}(D)+g_{3}(Z)\right]}
$$

Fig. 8 presents the shapes of $g_{1}(T), g_{2}(D)$ and $g_{3}(Z)$ for the rain hours at Florence. The spans $\lambda_{T}, \lambda_{D}$ and $\lambda_{Z}$ in the iterative smoothing procedure were again set equal to 0.5 here. From a comparison between the sample variances of the observed proportion of rain hours and the binomial variance for different categories of the predictor variables, the dispersion parameter $\sigma^{2}$ of these data was approximated as

$$
\sigma^{2}=5.047-0.101 T
$$

where $T$ is in ${ }^{\circ} \mathrm{C}$ (the average $\sigma^{2}$ is 3.67). $g_{1}(T)$ in Fig. 8 is a decreasing function. The mean rainfall duration decreases by about $9 \min (\sim 2.3 \%)$ if $\mathrm{T}$ increases by $1^{\circ} \mathrm{C}$ and $D$ and $Z$ remain unchanged (Appendix 1 ). Combining this decrease with an increase in $\mathrm{H}$ of $10.4 \%$ ${ }^{\circ} \mathrm{C}^{-1}$, results in an increase of $7.9 \%{ }^{\circ} \mathrm{C}^{-1}$ for $\mathrm{P}$, which is still larger than the increase of $6.0 \%{ }^{\circ} \mathrm{C}^{-1}$ from the direct fit to $P$. The relatively large variance of the esti- 
mated regression coefficients, departures from model assumptions and the fact that a day with rain hours is not always a wet day (amount of precipitation $0.3 \mathrm{~mm}$ or more) are responsible for the difference between the 2 estimates.

The differences between the functions $g_{2}(D)$ and $g_{3}(Z)$ for $P$ in Fig. 3 and $\mathrm{H}$ in Fig. 7 can similarly be explained. For instance, there is a positive relationship between the proportion of rain hours and $Z$ in Fig. 8, which enhances the increase of $\mathrm{H}$ with increasing $Z$, leading to a rather steep slope of $g_{3}(Z)$ in Fig. 3 for the wet-day precipitation amounts.

\section{DISCUSSION}

Precipitation and temperature are physically related through the dependence of atmospheric moisture on temperature. The link between the amount of precipitation and temperature is, however, often masked in observed records because of the influence of other factors on precipitation. For climate-change scenario development it may be extremely useful to make the precipitation-temperature dependence visible. This requires a proper selection of predictor variables. For Florence and Livorno it turned out that the difference, $D$, between the land and sea surface temperatures should be taken into account. The precipitation-temperature dependence could also be unmasked for the Durham data in Fig. 1 using $D$ as a predictor variable (Brandsma \& Buishand 1996). The statistical models used do not give more than a very simplified description of the effects of the land and sea surface temperatures and vorticity on precipitation. The estimated temperature effects on the amount of precipitation can therefore be biased. Another point is the rather strong correlation between $\mathrm{T}$ and $\mathrm{D}$. This correlation inflates the standard errors of the predicted mean precipitation amounts in situations where the changes in $T$ and $D$ differ from those expected from the observed statistical relationship between T and D (Hocking \& Pendleton 1983), such as a positive change in $T$ and no change in $D$. Rather long records are then required to keep these standard errors within reasonable limits.

A number of authors have used artificial neural networks to model the non-linear relationships between local precipitation and atmospheric variables (Cavazos 1997, Crane \& Hewitson 1998). Non-parametric smoothing is more flexible regarding non-normality and variance heterogeneity, and the form of the relationships is clearly shown. However, the iterative backfitting algorithm in this technique requires that the predictor effects can be modelled as a sum of smooth terms. Inclusion of interaction between predictor effects is not straightforward.
The regression models used here explain only a small proportion of the wet-day precipitation variance. They are therefore unsuitable to predict the amount of precipitation of a particular wet day, but they may provide realistic estimates of the change in the long-term mean wet-day precipitation amounts. An important condition is that the fitted relationship holds for the altered climate as well. For the relationships presented in this study, it would also be useful to know more about potential changes in D. GCM s may not simulate this well in the Mediterranean region due to resolution and land/sea mask limitations.

In Buishand \& Klein Tank (1996) and Brandsma \& Buishand (1997) the model fitted to the wet-day precipitation amounts was used to derive a scenario of daily precipitation in the case of a homogeneous temperature rise, $\Delta T$, over a large area by scaling the observed daily precipitation amounts with a temperature-dependent factor, $f$. This factor becomes a constant, $f=\exp (b \Delta T)$, if $g_{1}(T)=b T$ as in Eq. (12). The number of wet days remains unchanged in the resulting scenario. For the Italian data in this study, this is somewhat in conflict with the observed decrease in rainfall duration with increasing temperature in Fig. 8, which will generally result in less wet days. A decrease in the number of wet days at middle latitudes has also been found in some GCM simulations with increased atmospheric greenhouse gas concentrations (Hennessy et al. 1997). A systematic change in wet-day frequency will almost certainly occur if the temperature increase is accompanied by a change in the vorticity index, Z, or a change in D. A separate model that describes the dependence of daily rainfall occurrence on the predictor variables is then needed. Logistic regression can be used for that purpose (Klein Tank \& Buishand 1995).

Acknowledgements. The authors are grateful to P. Burlando (Politecnico di Milano, now at ETH Zürich) for making the Florence and Livorno data available. They further thank 3 anonymous reviewers for their comments on the manuscript. The UK Meteorological Office MSLP data and the Durham data were kindly provided by P. D. J ones (Climatic Research Unit, University of East Anglia, Norwich). The research was, in part, supported by the EC Environment Research Programme (contract: EV 5V-CT 94-0510, Climatology and Natural Hazards).

\section{LITERATURE CITED}

Bárdossy A, Plate EJ (1992) Space-time model for daily rainfall using atmospheric circulation patterns. Water Resour Res 28:1247-1259

Boer GJ (1993) Climate change and the regulation of the surface moisture and energy budgets. Clim Dyn 8:225-239

Bottomley M, Folland CK, Hsiung J, Newell RE, Parker DE (1990) Global ocean surface temperature atlas. UK M eteo- 
A ppendix 1. Change in rainfall duration

This appendix discusses the use of the logistic model in Eq. (13) to estimate the change in mean rainfall duration resulting from a temperature increase. For ease of notation the arguments of $\Pi$ are dropped.

The logit $Y$ is defined by

$$
Y=\ln [\Pi /(1-\Pi)]=a+g_{1}(T)+g_{2}(D)+g_{3}(Z)
$$

Let $\Pi^{*}$ be the value of $\Pi$ if temperature increases by $\Delta T$ while $D$ and $Z$ remain unchanged. The logit then becomes

$Y^{*}=\ln \left[\Pi^{*} /\left(1-\Pi^{*}\right)\right]=\mathrm{a}+\mathrm{g}_{1}(\mathrm{~T}+\Delta \mathrm{T})+\mathrm{g}_{2}(\mathrm{D})+\mathrm{g}_{3}(\mathrm{Z})(\mathrm{A} 2)$

From Eqs. (A1) \& (A2), it follows that

$$
\ln \left[\Pi^{*} /\left(1-\Pi^{*}\right)\right]=\ln [\Pi /(1-\Pi)]+g_{1}(T+\Delta T)-g_{1}(T)
$$

This can be rewritten as

$$
\Pi^{*}=\frac{\Pi \exp \left[g_{1}(T+\Delta T)-g_{1}(T)\right]}{1-\Pi+\Pi \exp \left[g_{1}(T+\Delta T)-g_{1}(T)\right]}
$$

Eq. (A4) ensures that $\Pi^{*}$ lies between 0 and 1 . The difference between $\Pi$ and $\Pi^{*}$ tends to be small if $\Pi$ is near 0 or 1 .

For Florence, Fig. 8 shows that $g_{1}(T)$ is almost linear. With $\mathrm{g}_{1}(\mathrm{~T})=\mathrm{bT}$, Eq. (A4) reduces to

$$
\Pi^{*}=\frac{\mathrm{h} \Pi}{1-\Pi+\mathrm{h} \Pi}
$$

where $h=\exp (b \Delta T)$. For Florence, the estimate of $b$ equals -0.0329 , giving $\mathrm{h}=0.9676$ for $\Delta \mathrm{T}=1^{\circ} \mathrm{C}$. From Eq. (A5) it follows for this temperature increment that the mean rainfall duration decreases by $4.2 \mathrm{~min}$ if $\Pi=0.1\left(\Pi^{*}=0.0971\right)$ and by $11.8 \mathrm{~min}$ if $\Pi=0.5\left(\Pi^{*}=0.4918\right)$. The average predicted proportion of rain hours at Florence is $\bar{\Pi}=0.2631$. For $\Pi=\bar{\Pi}$, and $h=0.9676$, Eq. (A5) gives $\Pi^{*}=0.2568$, which is close to the average $\bar{\Pi}^{*}=0.2570$. The difference $\bar{\Pi}^{*}-\bar{\Pi}$ corresponds to a decrease of about 9 min in mean rainfall duration. rological Office, Bracknell, and Massachusetts Institute of Technology, Cambridge, MA

Brandsma T, Buishand TA (1996) KNMI contribution to the European project POPSICLE. Tech Rep TR 194, KN MI, De Bilt

Brandsma T, Buishand TA (1997) Statistical linkage of daily precipitation in Switzerland to atmospheric circulation and temperature. J Hydrol 198:98-123

Buishand TA, Klein Tank AMG (1996) Regression model for generating time series of daily precipitation amounts for climate change impact studies. Stochast Hydrol Hydraul 10:87-106

Cavazos T (1997) Downscaling large-scale circulation to local winter rainfall in north-eastern M exico. Int J Climatol 17: 1069-1082

Chambers J M, Hastie TJ (1993) Statistical models in S. Chapman and Hall, London

Cleveland WS (1979) Robust locally weighted regression and smoothing scatterplots. J Am Stat Assoc 74:829-836

Crane RG, Hewitson BC (1998) Doubled $\mathrm{CO}_{2}$ precipitation changes for the Susquehanna basin: down-scaling from the Genesis general circulation model. Int J Climatol 18: 65-76

Cubasch U, von Storch H, Waszkewitz J , Zorita E (1996) Estimates of climate change in Southern Europe derived from dynamical climate model output. Clim Res 7:129-149

Frei C, Schär C, Lüthi D, Davies HC (1998) Heavy precipitation processes in a warmer climate. Geophys Res Lett 25: 1431-1434

Gaffen DJ , Elliott WP, Robock A (1992) Relationships between tropospheric water vapor and surface temperature as observed by radiosondes. Geophys Res Lett 19:1839-1842

Harzallah A, Sadourny R (1995) Internal versus SST-forced atmospheric variability as simulated by an atmospheric general circulation model. J Clim 8:474-495

Hastie TJ , Tibshirani RJ (1990) Generalized additive models. Chapman and Hall, London

Henderson-Sellers A, Howe W, McGuffie K (1995) The MECCA analysis project. Global Planet Change 10:3-21

Hennessy KJ, Gregory J M, Mitchell J FB (1997) Changes in daily precipitation under enhanced greenhouse conditions. Clim Dyn 13:667-680

Hocking RR, Pendleton OJ (1983) The regression dilemma.
Comm Stat Ser A 12:497-527

Hughes J P, Lettenmaier DP, Guttorp P (1993) A stochastic approach for assessing the effect of changes in synoptic circulation patterns on gauge precipitation. Water Resour Res 29:3303-3315

Hulme M (1994) Validation of large-scale precipitation fields in general circulation models. In: Desbois M, Désalmand $F$ (eds) Global precipitation and climate change, NATO ASI Series I: Global environmental change, Vol 26. SpringerVerlag, Berlin, p 389-405

Hulme M, Osborn TJ , J ohns TC (1998) Precipitation sensitivity to global warming: comparison of observations with HadCM 2 simulations. Geophys Res Lett 25:3379-3382

IPCC (Intergovernmental Panel on Climate Change) (1990) Climate change: the IPCC scientific assessment. Houghton J T, J enkins GJ , Ephraums JJ (eds). Cambridge University Press, Cambridge

IPCC (Intergovernmental Panel on Climate Change) (1992) Climate change 1992: the supplementary report to the IPCC scientific assessment. Houghton JT, Callander BA, Varney SK (eds). Cambridge University Press, Cambridge

J ones PD, Wigley TML, Farmer G (1991) Marine and land temperature data sets: a comparison and a look at recent trends. In: Schlessinger ME (ed) Greenhouse-gas-induced climate change: a critical appraisal of simulations and observations, Elsevier, Amsterdam, p 153-172

J ones PD, Hulme M, Briffa KR (1993) A comparison of Lamb circulation types with an objective classification scheme. Int J Climatol 13:655-663

J ones RG, M urphy J M, Noguer M, Keen AB (1997) Simulation of climate change over Europe using a nested regional-climate model. II: Comparison of driving and regional model responses to a doubling of carbon dioxide. Q J R M eteorol Soc 123:265-292

Klein Tank AMG, Buishand TA (1993) Modelling daily precipitation as a function of temperature for climate change impact studies. Sci Rep WR 93-02, KNMI, De Bilt

Klein Tank AM G, Buishand TA (1995) Transformation of precipitation time series for climate change impact studies. Sci Rep WR 95-01, KNMI, De Bilt

Matyasovszky I, Bogárdi I, Bárdossy A, Duckstein L (1993) Space-time precipitation reflecting climate change. Hydrol Sci J 38:539-558 
McCullagh P, Nelder J A (1989) Generalized linear models, 2nd edn. Chapman and Hall, London

Schär C, Frei C, Lüthi D, Davies HC (1996) Surrogate climatechange scenarios for regional climate models. Geophys Res Lett 23:669-672

von Storch H, Zorita E, Cubasch U (1993) Downscaling of

Editorial responsibility: Hans von Storch, Geesthacht, Germany global climate change estimates to regional scales: an application to Iberian rainfall in wintertime. J Clim 6: 1161-1171

Wilby RL, Wigley TML (1997) Downscaling general circulation model output: a review of methods and limitations. Prog Phys Geogr 21:530-548

Submitted: J uly 30, 1998; Accepted: M arch 15, 1999

Proofs received from author(s): A pril 27, 1999 